\title{
Excellence in Research for Australia: An Audit of the Applied Economics Rankings
}

\author{
Sinclair Davidson ${ }^{1}$
}

\section{Abstract}

The Excellence in Research for Australia (ERA) Report attempts to quantify the quality of research undertaken in Australian universities in the field of 'Applied Economics'. The paper shows it is difficult to reconcile the ERA rankings with the underlying data drawn from the Scopus database. Since the ERA rankings cannot be replicated, and since the $E R A$ process is non-transparent, its rankings should be treated with some caution.

\section{Introduction}

The second Excellence in Research for Australia (ERA) National Report was released in December 2012. The importance of this Report cannot be understated. It will be used to allocate government funding to universities and also to separate out 'top performers' from 'also-rans'. As Stephen Matchett (2012b) of The Australian wrote:

Anybody contemplating an MBA can use ERA 2012 to assess every university claims that its bized (sic) staff are world-class researchers; in most cases they aren't. Have a look at the commerce and management list, there is a majority of low and no scores.

And the elite institutions can make the case they deserve all public research money, given they do so much of the world-class work. Of course everybody else can argue that the presence of Wollongong and Macquarie among the top performers makes the case for Canberra spreading the cash about. But that is an argument which applies to those two, not the 20 or so also-rans.

\footnotetext{
1 RMIT University, sinclair.davidson@rmit.edu.au. I thank William Coleman, Ashton de Silva, and two anonymous referees for valuable comments on an earlier draft of this paper.
} 
Some have gone further; Peter Roberts (2012) writing for the Australian Financial Review has used the 2010 ERA results to discredit policy advice given by Australian economists.

The average ranking of all fields of Australian research ERA measured was 3.4 on a scale of five, a score not achieved by any of the four measured strands of local economics.

Applied economics and other economics rated 2.1 and 2 respectively with any rating in the twos indicating a field which is performing below world average quality. Economic theory rated 3.1 and econometrics 3.3 which, while considered world average, were nevertheless below the Australian academic average.

Finally, of the 35 universities teaching economics here, ERA rated only seven institutions as above or well above world average quality; 14 received a score of 1 , very much below world average quality.

At the same time, the ERA exercise has quickly gained broad acceptance. As The Australian's Matchett (2012a) explains: 'ERA doesn't just quantify research output it measures productivity. Which will upset academics who never quite get around to writing anything.'

In plain language: anyone speaking out against the ERA must either be bone idle or simply making excuses for underperformance.

The reality is that the ERA report results rely on some courageous assumptions. First, that government (or its agencies) can define quality. Second, that government (or its agencies) can measure quality. Third, that quality can be sufficiently represented in a single number between 1 and 5 .

In this critique I do not challenge these fundamental assumptions, important as they are. Nor do I attempt to critique the ERA ranking process relative to the existing literature that attempts to provide similar rankings (for example, see Rodgers and Valadkhanim 2006 for a recent Australian example of this literature). I simply investigate whether ERA rankings are consistent with objective information.

To that end, I calculate the average citations for articles published between 2005 and 2010 for the 30 Australian universities that have a 2012 ERA ranking in the area of 'Applied Economics'. I employ the same global database that the ERA uses. I investigate that data along with an alternative measure of quality (the H-Index). Finally, I relate the ERA rank to the objective data I have gathered and discuss the anomalous results. 
In short, it is difficult to reconcile the published ERA rankings with the objective data that the ERA claims as being an input into its ranking process. Some universities are ranked well above the level we might otherwise expect, while others well below the level we might expect.

\section{The ERA process}

The ERA 2012 Evaluation Handbook claims several objectives, with the first being: ${ }^{2}$

- Establish an evaluation framework that gives government, industry, business and the wider community assurance of the excellence of research conducted in Australia's higher education institutions.

To that end, the ERA defines a five-point scale:

5. '... well above world standard ...'

4. '... above world standard ...'

3. '... at world standard ...'

2. '... below world standard ...'

1. '... well below world standard ...'

It is quite remarkable that the ERA does not define what 'world standard' is, but rather tells us what it is not. ${ }^{3}$ We are told, "WWorld Standard" refers to a quality standard. It does not refer to the nature or geographical scope of particular subjects, nor to the locus of research nor its place of dissemination.' As reassuring as that is, there is still no definition of the 'quality standard' that 'world standard' entails. Further, 'The ERA evaluation measures research quality, not scale or productivity.' Indeed, 'The methodology and rating scale allow for [units of evaluation] with different volumes of output to achieve the same rating.'

Universities submit data to the Australian Research Council (ARC) that administers the ERA. That data relate to so-called Units of Evaluation - that is, a research discipline within a university. That Unit of Evaluation need not be a single department or school within a university. The Australian Research Council recruits individuals for Research Evaluation Committees and individuals

2 Handbook: 3.

3 Ibid: $22-3$. 
who undertake peer review. Evaluation takes place, outcomes are determined, and results are published. The peer reviewers and members of the Research Evaluation Committees are bound by very strict confidentiality clauses. ${ }^{4}$

[Research Evaluation Committee] members and Peer Reviewers are required to sign a confidentiality agreement with the ARC prior to their participation in ERA. The agreement covers all aspects of their work with ERA, and the agreement survives the conclusion of their engagement for the purposes of ERA.

[Research Evaluation Committee] members and Peer Reviewers may not contact researchers and/or institutions under any circumstances in relation to material that has been submitted for evaluation in ERA, or seek additional information from any sources. [Research Evaluation Committee] members and Peer Reviewers may not reveal details about any evaluation at any time. ${ }^{5}$

The most important consideration, however, is this (emphasis added):

[Research Evaluation Committee] members exercise their knowledge, judgement and expertise to reach a single rating for each [Unit of Evaluation]. ... The rating for each [Unit of Evaluation] reflects the [Research Evaluation Committee] members' expert and informed view of the characteristics of the [Unit of Evaluation] as a whole.

In other words, the 'evaluation framework' that the ERA provides is not a transparent and replicable process; but, rather, an exercise where unknown individuals, acting in secret, selected by the government (or its agencies), express an opinion as to the quality of research relative to an undefined benchmark.

The ERA claims to have calculated 'Indicator principles' that are quantitative and 'internationally recognised' ${ }^{6}$ To that end the ERA undertakes a citation analysis using the world-recognised Scopus database. According to its blurb, this database is 'the largest abstract and citation database of peer-reviewed research literature with more than 20500 titles from more than 5000 international publishers. Scopus offers researchers a quick, easy and comprehensive resource to support their research needs in the scientific, technical, medical and social sciences fields and arts and humanities. ${ }^{7}$

4 Ibid: 12 .

5 I had been a Peer Reviewer in 2010 and was approached to be a Peer Reviewer in 2012. Upon reflection I refused to agree to the confidentiality clause.

6 Handbook: 21.

7 http://www.info.sciverse.com/scopus/scopus-in-detail/facts. 
ERA interrogated Scopus as at 1 March 2012 to calculate the following citation count:

(1) World benchmark = [Sum of cites for all eligible articles in world data set] / [Total sum of eligible articles in world data set].

The ERA process is quite complicated but is more or less a citation count. It is possible to undertake a back-of-the-envelope replication of that process. In the next section I perform that back-of-the-envelope calculation for the Field of Research (FoR) code 1402 'Applied Economics'.

\section{Benchmarking the 2012 ERA results for Applied Economics}

Table 1 below shows the overall ERA results for 'Economics' as a discipline, together with the various sub-disciplines that make up 'Economics'. While I concentrate on the 'Applied Economics' results (third column), I quickly wish to discuss some of the (other) anomalous results that are immediately apparent in the table. For example, both Flinders University and the University of Newcastle have overall scores, but no individual score in any of the sub-disciplines. There is no obvious explanation as to how that could occur. On the other hand, there are several universities that have multiple scores in the sub-categories but there is no discussion as to how those scores were aggregated to an overall score. This is problematic; consider The Australian National University and the University of New South Wales. Both those institutions have identical scores in the subcategories but overall The Australian National University scores ' 5 ', while the University of New South Wales scores ' 4 '. Finally, some universities have lower overall scores than the subcategory scores would suggest (James Cook University, University of Canberra and University of Wollongong). Each of those universities has a lower overall score than its subcategory scores would have suggested.

8 The Economics discipline has the Field of Research code '14'. Within that Field is the sub-field 'Applied Economics' with a Field of Research code '1402'. The other fields are 'Economic Theory' code '1401', 'Econometrics' code '1403' and 'Other Economics' code '1499'. I have chosen Field of Research code '1402' for my analysis. 
Table 1: ERA gradings of economic research by university and field of research

\begin{tabular}{|c|c|c|c|c|c|}
\hline & 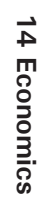 & 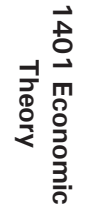 & 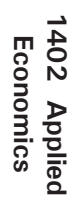 & 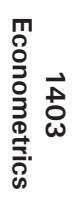 & 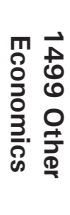 \\
\hline Australian National University & 5 & 4 & 4 & 5 & $\mathrm{n} / \mathrm{a}$ \\
\hline Bond University & 2 & $\mathrm{n} / \mathrm{a}$ & 2 & $\mathrm{n} / \mathrm{a}$ & $\mathrm{n} / \mathrm{a}$ \\
\hline Central Queensland University & 2 & $\mathrm{n} / \mathrm{a}$ & 2 & $\mathrm{n} / \mathrm{a}$ & $\mathrm{n} / \mathrm{a}$ \\
\hline Charles Darwin University & 3 & $\mathrm{n} / \mathrm{a}$ & 3 & $\mathrm{n} / \mathrm{a}$ & $\mathrm{n} / \mathrm{a}$ \\
\hline Charles Sturt University & 2 & $\mathrm{n} / \mathrm{a}$ & 2 & $\mathrm{n} / \mathrm{a}$ & $\mathrm{n} / \mathrm{a}$ \\
\hline Curtin University of Technology & 2 & $\mathrm{n} / \mathrm{a}$ & 2 & 2 & $\mathrm{n} / \mathrm{a}$ \\
\hline Deakin University & 3 & $\mathrm{n} / \mathrm{a}$ & 3 & $\mathrm{n} / \mathrm{a}$ & $\mathrm{n} / \mathrm{a}$ \\
\hline Edith Cowan University & 2 & $\mathrm{n} / \mathrm{a}$ & 2 & $\mathrm{n} / \mathrm{a}$ & $\mathrm{n} / \mathrm{a}$ \\
\hline Flinders University & 3 & $\mathrm{n} / \mathrm{a}$ & $\mathrm{n} / \mathrm{a}$ & $\mathrm{n} / \mathrm{a}$ & $\mathrm{n} / \mathrm{a}$ \\
\hline Griffith University & 2 & $\mathrm{n} / \mathrm{a}$ & 2 & $\mathrm{n} / \mathrm{a}$ & $\mathrm{n} / \mathrm{a}$ \\
\hline James Cook University & 1 & $\mathrm{n} / \mathrm{a}$ & 2 & $\mathrm{n} / \mathrm{a}$ & $\mathrm{n} / \mathrm{a}$ \\
\hline La Trobe University & 3 & $\mathrm{n} / \mathrm{a}$ & 3 & $\mathrm{n} / \mathrm{a}$ & $\mathrm{n} / \mathrm{a}$ \\
\hline Macquarie University & 3 & $\mathrm{n} / \mathrm{a}$ & 3 & $\mathrm{n} / \mathrm{a}$ & $\mathrm{n} / \mathrm{a}$ \\
\hline Monash University & 5 & $\mathrm{n} / \mathrm{a}$ & 4 & 5 & $\mathrm{n} / \mathrm{a}$ \\
\hline Queensland University of Technology & 3 & $\mathrm{n} / \mathrm{a}$ & 3 & $\mathrm{n} / \mathrm{a}$ & $\mathrm{n} / \mathrm{a}$ \\
\hline RMIT University & 2 & $\mathrm{n} / \mathrm{a}$ & 2 & $\mathrm{n} / \mathrm{a}$ & $\mathrm{n} / \mathrm{a}$ \\
\hline University of Adelaide & 4 & $\mathrm{n} / \mathrm{a}$ & 4 & $\mathrm{n} / \mathrm{a}$ & $\mathrm{n} / \mathrm{a}$ \\
\hline University of Ballarat & 2 & 2 & $\mathrm{n} / \mathrm{a}$ & $\mathrm{n} / \mathrm{a}$ & $\mathrm{n} / \mathrm{a}$ \\
\hline University of Canberra & 1 & $\mathrm{n} / \mathrm{a}$ & 2 & $\mathrm{n} / \mathrm{a}$ & $\mathrm{n} / \mathrm{a}$ \\
\hline University of Melbourne & 5 & 5 & 4 & 5 & $\mathrm{n} / \mathrm{a}$ \\
\hline University of New England & 2 & $\mathrm{n} / \mathrm{a}$ & 2 & $\mathrm{n} / \mathrm{a}$ & $\mathrm{n} / \mathrm{a}$ \\
\hline University of New South Wales & 4 & 4 & 4 & 5 & $\mathrm{n} / \mathrm{a}$ \\
\hline University of Newcastle & 1 & $\mathrm{n} / \mathrm{a}$ & $\mathrm{n} / \mathrm{a}$ & $\mathrm{n} / \mathrm{a}$ & $\mathrm{n} / \mathrm{a}$ \\
\hline University of Queensland & 4 & 5 & 4 & 4 & $\mathrm{n} / \mathrm{a}$ \\
\hline University of South Australia & 3 & $\mathrm{n} / \mathrm{a}$ & 3 & $\mathrm{n} / \mathrm{a}$ & $\mathrm{n} / \mathrm{a}$ \\
\hline University of Southern Queensland & 2 & $\mathrm{n} / \mathrm{a}$ & 2 & $\mathrm{n} / \mathrm{a}$ & $\mathrm{n} / \mathrm{a}$ \\
\hline University of Sydney & 4 & 3 & 4 & 4 & $\mathrm{n} / \mathrm{a}$ \\
\hline $\begin{array}{l}\text { University of Tasmania (inc. Australiar } \\
\text { College) }\end{array}$ & 2 & $\mathrm{n} / \mathrm{a}$ & 2 & $\mathrm{n} / \mathrm{a}$ & $\mathrm{n} / \mathrm{a}$ \\
\hline University of Technology, Sydney & 5 & $\mathrm{n} / \mathrm{a}$ & 5 & 5 & $\mathrm{n} / \mathrm{a}$ \\
\hline University of Western Australia & 4 & $\mathrm{n} / \mathrm{a}$ & 4 & $\mathrm{n} / \mathrm{a}$ & $\mathrm{n} / \mathrm{a}$ \\
\hline University of Western Sydney & 2 & 1 & 2 & $\mathrm{n} / \mathrm{a}$ & $\mathrm{n} / \mathrm{a}$ \\
\hline University of Wollongong & 2 & $\mathrm{n} / \mathrm{a}$ & 3 & $\mathrm{n} / \mathrm{a}$ & $\mathrm{n} / \mathrm{a}$ \\
\hline Victoria University & 2 & $\mathrm{n} / \mathrm{a}$ & 2 & $\mathrm{n} / \mathrm{a}$ & $\mathrm{n} / \mathrm{a}$ \\
\hline Total UoEs evaluated & 33 & 7 & 30 & 8 & 0 \\
\hline
\end{tabular}


According to the ERA, there were 3765.3 journal articles submitted by Australian universities in the category 1402 'Applied Economics'. There were also 112.1 books, 926.5 book chapters, 511.9 conference papers and 41.9 non-traditional research outputs submitted for evaluation. (The fractions are explained by universities submitting the same research output in more than one category.)

I accessed the Scopus database and undertook a search for all articles that can be described as being 'Applied Economics"' over the period 2006-10. ${ }^{9}$ I collected for each university (i) the number of articles recorded by Scopus (henceforth 'Documents'), (ii) the number of citations reported by Scopus (henceforth 'Citations'), and (iii) the H-Index calculated by Scopus (henceforth 'H-Index'). ${ }^{10}$ Finally, I have calculated the average number of citations by dividing the sum of citations by the sum of articles (henceforth 'Average-Cites'). I calculated these four metrics for each of the 30 Australian universities that have an ERA score for '1402 Applied Economics' (see Table 1) and report them in Table 2. ${ }^{11}$

The first thing to note is that there are far fewer documents recorded in Scopus than the number of items Australian universities have submitted for evaluation. That could be explained by Scopus' limited coverage relative to the ERA list of journals. That suggests that Scopus may not be as reliable in this analysis as may have been hoped. It also suggests that any articles not published in a Scopus journal and/or not referenced in Scopus journals are likely to be undervalued by this process.

The raw data of Table 2 also suggests some interesting anomalies. For example, 'Applied Economics' research at Charles Darwin University is ranked by the ERA as being at the world standard. Yet over a six-year period up to December 2012 it has just one article in the Scopus database; an article that has received just four citations. It may be the case that Charles Darwin University has a (large) number of articles not published in Scopus-listed journals, and that these papers, in turn, were heavily cited by those very journals. ${ }^{12}$ Similarly, the University of Technology, Sydney with a mere 20 articles, 241 citations, and an

9 While the ERA analysis is at 1 March 2012, my analysis is at 8 December 2012. I have a slightly longer timeframe, but given that most journals appear quarterly (and sometimes less frequently) I have less additional information than the nine-month difference indicates.

10 The H-Index is described at http://en.wikipedia.org/wiki/H-index. An academic with an index of $h$ will have published $h$ papers each of which has been cited at least $h$ times.

11 Over that six-year period the Scopus database has 15848 articles that, in some way, can be described as being 'Applied Economics'. Those 15848 articles have been cited 64362 times. Using equation (1) above, that implies an average citation rate of 4.06. That rate, however, is biased - articles published in 2006, for example, have been cited on average 10.1 times, while articles published in 2010 had only been published 0.91 times. Quite clearly there are publication and citation lags. That is to be expected and the ERA acknowledges that lag. Results of this exercise are shown in Table 2. ERA also calculated equation (1) on a year-by-year basis while I have only calculated it for the entire period 2005-10. The year-by-year analysis would sum up to the score I have calculated.

12 There is a low-volume threshold that must be reached before any analysis can occur. According to the Handbook (p.5), that threshold is 50 research outputs. 
H-Index of 8 (barely at the Australian average) has earned an ERA ranking of 5 - 'well above the world standard'. They too may have a number of articles not published in Scopus-linked journals that have in turn been cited by Scopuslinked journals. That sort of argument, however, cannot explain why Griffith University has 114 articles, 1157 citations, and an H-Index of 18 yet is scored 'below world standard' on its research by ERA.

Table 2: Measures of research performance in Applied Economics from Scopus

\begin{tabular}{|c|c|c|c|c|c|}
\hline Institution & 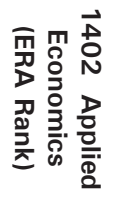 & 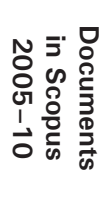 & 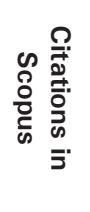 & 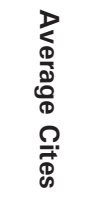 & $\begin{array}{l}\frac{I}{\frac{1}{3}} \\
\frac{2}{\mathbb{Q}}\end{array}$ \\
\hline Australian National University & 4 & 89 & 599 & 6.73 & 13 \\
\hline Bond University & 2 & 14 & 109 & 7.79 & 6 \\
\hline Central Queensland University & 2 & 8 & 50 & 6.25 & 8 \\
\hline Charles Darwin University & 3 & 1 & 4 & 4.00 & 1 \\
\hline Charles Sturt University & 2 & 16 & 234 & 14.63 & 6 \\
\hline Curtin University of Technology & 2 & 44 & 95 & 2.16 & 5 \\
\hline Deakin University & 3 & 74 & 589 & 7.96 & 13 \\
\hline Edith Cowan University & 2 & 15 & 55 & 3.67 & 4 \\
\hline Griffith University & 2 & 114 & 1157 & 10.15 & 18 \\
\hline James Cook University & 2 & 11 & 273 & 24.82 & 6 \\
\hline La Trobe University & 3 & 31 & 188 & 6.06 & 8 \\
\hline Macquarie University & 3 & 29 & 85 & 2.93 & 6 \\
\hline Monash University & 4 & 189 & 1708 & 9.04 & 23 \\
\hline Queensland University of Technology & 3 & 25 & 250 & 10.00 & 10 \\
\hline RMIT University & 2 & 40 & 257 & 6.43 & 8 \\
\hline University of Adelaide & 4 & 30 & 137 & 4.57 & 6 \\
\hline University of Canberra & 2 & 7 & 11 & 1.57 & 2 \\
\hline University of Melbourne & 4 & 91 & 481 & 5.29 & 11 \\
\hline University of New England & 2 & 20 & 259 & 12.95 & 7 \\
\hline University of New South Wales & 4 & 44 & 224 & 5.09 & 8 \\
\hline University of Queensland & 4 & 83 & 597 & 7.19 & 11 \\
\hline University of South Australia & 3 & 25 & 145 & 5.80 & 7 \\
\hline University of Southern Queensland & 2 & 4 & 17 & 4.25 & 3 \\
\hline University of Sydney & 4 & 42 & 367 & 8.74 & 9 \\
\hline $\begin{array}{l}\text { University of Tasmania (inc. Australian } \\
\text { Maritime College) }\end{array}$ & 2 & 13 & 191 & 14.69 & 3 \\
\hline University of Technology, Sydney & 5 & 20 & 241 & 12.05 & 8 \\
\hline
\end{tabular}




\begin{tabular}{|c|c|c|c|c|c|}
\hline Institution & 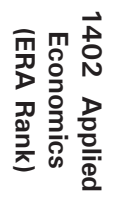 & 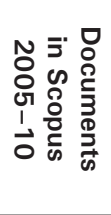 & 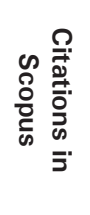 & 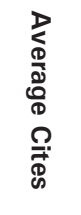 & 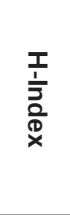 \\
\hline University of Western Australia & 4 & 72 & 518 & 7.19 & 11 \\
\hline University of Western Sydney & 2 & 33 & 88 & 2.67 & 5 \\
\hline University of Wollongong & 3 & 34 & 129 & 3.79 & 6 \\
\hline Victoria University & 2 & 58 & 325 & 5.60 & 10 \\
\hline Total UoEs evaluated & 30 & 1276 & 9383 & 7.35 & 8.07 \\
\hline
\end{tabular}

Source: ERA, Scopus, Author's calculations.

I then calculate a correlation matrix to investigate the relationships between the data. The result of that exercise is shown in Table 3.

Table 3: Correlations of ERA rankings with Scopus Performance Metrics (p statistics in parentheses)

\begin{tabular}{lcccc}
\hline & Documents & Citations & Ave_Cites & H-Index \\
\hline ERA Rank & 0.4147 & 0.3329 & -0.0756 & 0.3966 \\
& $(0.0230)$ & $(0.0720)$ & $(0.6910)$ & $(0.0300)$ \\
Documents & & 0.9411 & -0.0263 & 0.9218 \\
& & $(0.0000)$ & $(0.8900)$ & $(0.0000)$ \\
Citations & & 0.2261 & 0.9380 \\
& & & $(0.2300)$ & $(0.0000)$ \\
Ave_Cites & & & 0.1540 \\
& & & & $(0.4160)$ \\
\hline
\end{tabular}

Source: ERA, Scopus, Author's calculations.

The single largest correlation with the ERA Rank is the number of documents contained in the Scopus dataset. While the ERA has emphasised that it intends to measure quality and not quantity, this result is not problematic. It is quite likely that more articles published in journals tracked by the Scopus database is itself an indicator of quality. At the very least it is likely to be a proxy for quality (Silva 2012). That does, however, raise questions about the ERA's rankings of institutions such as Charles Darwin University and the University of Technology, Sydney.

The second-largest correlation with the ERA Rank is H-Index. This is entirely expected - the H-Index is a measure of quality. If anything, it is somewhat surprising that the correlation is as low as it is and is not higher. Similarly, the third-highest correlation with the ERA Rank - Citations - is expected. What is somewhat surprising is the small, negative, and not statistically significant correlation between ERA Rank and average citations. That measure is derived 
from equation (1) - the very measure the ERA employed as its 'World citations per paper benchmark'. ${ }^{13}$ The low correlation between the ERA benchmark and the well-known H-Index is also somewhat troubling.

Next Table 4 shows some summary statistics for the data I have extracted from Scopus relative to the ERA Ranks. The first thing to note is that there is no monotonic increase in any of the measures across the four ERA Ranks. The single university awarded a rank of 5 (University of Technology, Sydney) underperforms the eight universities with a rank of 4 in three of the four measures. It is only for Average Citations that the University of Technology, Sydney outperforms the eight universities in the 4 ranking. In that metric, however, the 14 universities ranked 2 outperform the seven universities ranked 3. Overall there is no clear relationship between the ERA Ranks and the data extracted from Scopus.

Table 4: Scopus performance metrics by ERA rank

\begin{tabular}{|c|c|c|c|c|c|c|}
\hline & ERA Rank & 2 & 3 & 4 & 5 & ALL \\
\hline \multirow{6}{*}{ 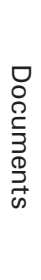 } & Mean & 28.4 & 31.3 & 80.0 & 20.0 & 42.5 \\
\hline & Median & 15.5 & 29.0 & 77.5 & 20.0 & 30.5 \\
\hline & Maximum & 114.0 & 74.0 & 189.0 & 20.0 & 189.0 \\
\hline & Minimum & 4.0 & 1.0 & 30.0 & 20.0 & 1.0 \\
\hline & Std. Dev. & 29.4 & 21.7 & 49.9 & & 40.2 \\
\hline & $\mathrm{N}$ & 14 & 7 & 8 & 1 & 30 \\
\hline \multirow{6}{*}{ 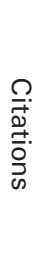 } & Mean & 222.9 & 198.6 & 578.9 & 241.0 & 312.8 \\
\hline & Median & 150.0 & 145.0 & 499.5 & 241.0 & 229.0 \\
\hline & Maximum & 1157.0 & 589.0 & 1708.0 & 241.0 & 1708.0 \\
\hline & Minimum & 11.0 & 4.0 & 137.0 & 241.0 & 4.0 \\
\hline & Std. Dev. & 288.5 & 188.7 & 486.2 & & 358.5 \\
\hline & $\mathrm{N}$ & 14 & 7 & 8 & 1 & 30 \\
\hline \multirow{6}{*}{ 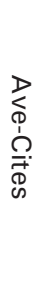 } & Mean & 8.4 & 5.8 & 6.7 & 12.1 & 7.5 \\
\hline & Median & 6.3 & 5.8 & 7.0 & 12.1 & 6.3 \\
\hline & Maximum & 24.8 & 10.0 & 9.0 & 12.1 & 24.8 \\
\hline & Minimum & 1.6 & 2.9 & 4.6 & 12.1 & 1.6 \\
\hline & Std. Dev. & 6.5 & 2.5 & 1.7 & & 4.8 \\
\hline & $\mathrm{N}$ & 14 & 7 & 8 & 1 & 30 \\
\hline \multirow{6}{*}{$\begin{array}{l}\frac{I}{\frac{1}{2}} \\
\frac{0}{\mathbb{D}} \\
\times\end{array}$} & Mean & 6.5 & 7.3 & 11.5 & 8.0 & 8.1 \\
\hline & Median & 6.0 & 7.0 & 11.0 & 8.0 & 7.5 \\
\hline & Maximum & 18.0 & 13.0 & 23.0 & 8.0 & 23.0 \\
\hline & Minimum & 2.0 & 1.0 & 6.0 & 8.0 & 1.0 \\
\hline & Std. Dev. & 4.0 & 3.7 & 5.1 & & 4.6 \\
\hline & $\mathrm{N}$ & 14 & 7 & 8 & 1 & 30 \\
\hline
\end{tabular}

Source: ERA, Scopus, Author's calculations. 
It is possible to display the data visually. ${ }^{14}$ The box and whisker plots (see Figure 1) demonstrate the similarities between the various measures as opposed to the differences. In terms of Documents, Citations and H-Index, it is unlikely that the data statistically significantly differentitate Rank 2, Rank 3, and Rank 5. Placing that in context, it appears there is no difference between those universities ranked by the ERA as being below world standard and well above world standard. On the other hand, those eight universities merely 'above the world standard' (Rank 4) perform better than University of Technology, Sydney, which is ranked 'well above the world standard'.

By contrast, on Average Citations there is unlikely to be a statistically significant difference between those universities with Rank 2, Rank 3, and Rank 4. But 2 is 'below world average', while 4 is 'above world average'. There is little to separate the 30 institutions from each other, yet the ERA has been able to rank them from 'below world standard' to 'well above world standard'.

I then use the data collected from the Scopus database to estimate the simple Ordinary Least Squares regressions shown in Table $5 .{ }^{15}$ The regressions are ranked in terms of their Adjusted $\mathrm{R}^{2}$ measures. The values in parenthesis are p-values.

Table 5: Scopus performance metrics as a predictor of ERA rank

\begin{tabular}{|c|c|c|}
\hline Model 1 & $\begin{array}{c}\text { ERA Rank }=2.455630+0.009664 \text { Documents } \\
(0.0000) \quad(0.0227)\end{array}$ & $A d j-R^{2}=0.142378$ \\
\hline Model 2 & $\begin{array}{r}\text { ERA Rank }=2.210717+0.081316 \mathrm{H}-\text { Index } \\
(0.0000) \\
(0.0300)\end{array}$ & Adj- $R^{2}=0.127214$ \\
\hline Model 3 & $\begin{array}{r}\text { ERA Rank }=2.594483+0.000870 \text { Citations } \\
(0.0000) \quad(0.0722)\end{array}$ & Adj- $R^{2}=0.079066$ \\
\hline Model 4 & $\begin{array}{c}\text { ERA Rank }=2.977474-0.014837 \text { Ave_Cites } \\
(0.0000) \quad(0.6914)\end{array}$ & Adj- $R^{2}=-0.029799$ \\
\hline
\end{tabular}

Source: ERA, Scopus, Author's calculations.

Table 5 reveals that Average Citations has zero predictive power with respect to ERA rankings. The coefficient on Average Citations is negative, but not statistically significantly different from zero. This confirms the previous analysis suggesting that there is no relationship between the ERA ranks and the citation measure that the ERA employs in its analysis. In addition the Citations variable is only statistically significantly different from zero at the 10 per cent level.

\footnotetext{
14 I thank Ashton de Silva for providing the box and whisker plots.

15 Strictly speaking OLS is not entirely appropriate for this purpose - the dependent variable is discreet and bound between 1 and 5. An ordered choice model would be more appropriate; however, when I perform that exercise the coefficients are not statistically significantly different from zero.
} 


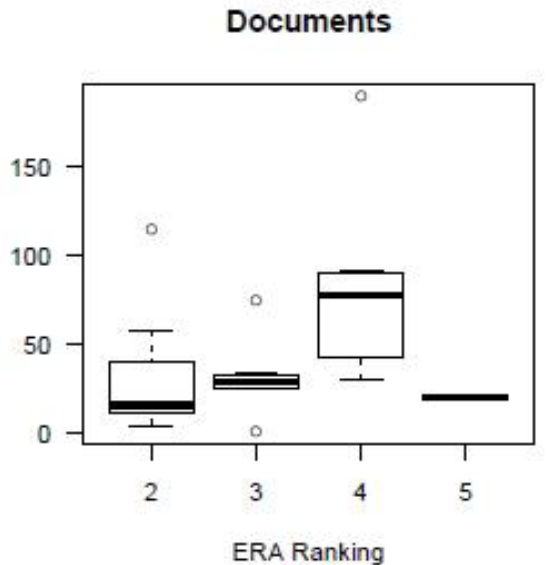

Average Citations

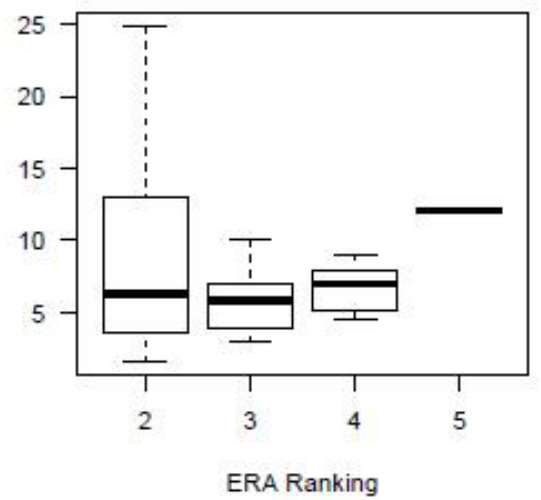

Citations

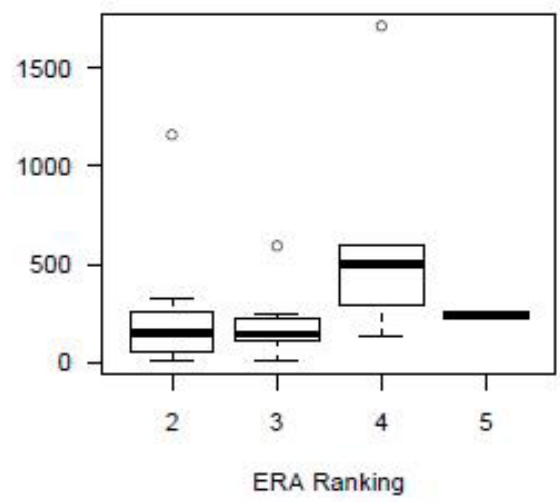

$\mathrm{H}-$ Index

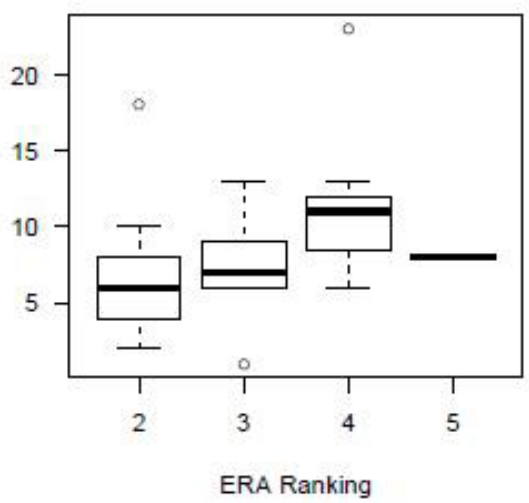

\section{Figure 1: Box and whisker plots}

Source: Ashton de Silva (see p15, footnote 14).

But the Documents variable and the H-Index variable are both statistically significantly different from zero at the 5 per cent level. Thus Model 1 (Documents variable) and Model 2 (H-Index variable) are my preferred model specifications in the analysis that follows. Model 3 (Citations) and Model 4 (Average Citations) are shown for completeness. 


\begin{tabular}{|c|c|c|c|c|c|c|c|c|c|}
\hline Institution & 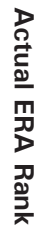 & 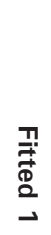 & $\begin{array}{l}\frac{T}{\vec{*}} \\
\frac{0}{2} \\
N\end{array}$ & $\begin{array}{l}\frac{T}{\vec{*}} \\
\frac{0}{\omega} \\
\omega\end{array}$ & 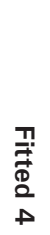 & 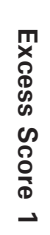 & 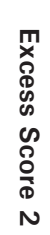 & 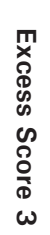 & 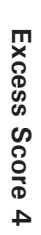 \\
\hline Australian National University & 4 & 3 & 3 & 3 & 3 & 1 & 1 & 1 & 1 \\
\hline Bond University & 2 & 3 & 3 & 3 & 3 & -1 & -1 & -1 & -1 \\
\hline Central Queensland University & 2 & 3 & 3 & 3 & 3 & -1 & -1 & -1 & -1 \\
\hline Charles Darwin University & 3 & 2 & 2 & 3 & 3 & 1 & 1 & 0 & 0 \\
\hline Charles Sturt University & 2 & 3 & 3 & 3 & 3 & -1 & -1 & -1 & -1 \\
\hline Curtin University of Technology & 2 & 3 & 3 & 3 & 3 & -1 & -1 & -1 & -1 \\
\hline Deakin University & 3 & 3 & 3 & 3 & 3 & 0 & 0 & 0 & 0 \\
\hline Edith Cowan University & 2 & 3 & 3 & 3 & 3 & -1 & -1 & -1 & -1 \\
\hline Griffith University & 2 & 4 & 4 & 4 & 3 & -2 & -2 & -2 & -1 \\
\hline James Cook University & 2 & 3 & 3 & 3 & 3 & -1 & -1 & -1 & -1 \\
\hline La Trobe University & 3 & 3 & 3 & 3 & 3 & 0 & 0 & 0 & 0 \\
\hline Macquarie University & 3 & 3 & 3 & 3 & 3 & 0 & 0 & 0 & 0 \\
\hline Monash University & 4 & 4 & 4 & 4 & 3 & 0 & 0 & 0 & 1 \\
\hline Queensland University of Technology & 3 & 3 & 3 & 3 & 3 & 0 & 0 & 0 & 0 \\
\hline RMIT University & 2 & 3 & 3 & 3 & 3 & -1 & -1 & -1 & -1 \\
\hline University of Adelaide & 4 & 3 & 3 & 3 & 3 & 1 & 1 & 1 & 1 \\
\hline University of Canberra & 2 & 3 & 2 & 3 & 3 & -1 & 0 & -1 & -1 \\
\hline University of Melbourne & 4 & 3 & 3 & 3 & 3 & 1 & 1 & 1 & 1 \\
\hline University of New England & 2 & 3 & 3 & 3 & 3 & -1 & -1 & -1 & -1 \\
\hline University of New South Wales & 4 & 3 & 3 & 3 & 3 & 1 & 1 & 1 & 1 \\
\hline University of Queensland & 4 & 3 & 3 & 3 & 3 & 1 & 1 & 1 & 1 \\
\hline University of South Australia & 3 & 3 & 3 & 3 & 3 & 0 & 0 & 0 & 0 \\
\hline University of Southern Queensland & 2 & 2 & 2 & 3 & 3 & 0 & 0 & -1 & -1 \\
\hline University of Sydney & 4 & 3 & 3 & 3 & 3 & 1 & 1 & 1 & 1 \\
\hline $\begin{array}{l}\text { University of Tasmania (inc. Australian } \\
\text { Maritime College) }\end{array}$ & 2 & 3 & 2 & 3 & 3 & -1 & 0 & -1 & -1 \\
\hline University of Technology, Sydney & 5 & 3 & 3 & 3 & 3 & 2 & 2 & 2 & 2 \\
\hline University of Western Australia & 4 & 3 & 3 & 3 & 3 & 1 & 1 & 1 & 1 \\
\hline University of Western Sydney & 2 & 3 & 3 & 3 & 3 & -1 & -1 & -1 & -1 \\
\hline University of Wollongong & 3 & 3 & 3 & 3 & 3 & 0 & 0 & 0 & 0 \\
\hline Victoria University & 2 & 3 & 3 & 3 & 3 & -1 & -1 & -1 & -1 \\
\hline
\end{tabular}

Source: ERA, Scopus, Author's calculations. 
Table 6 reports the ERA rank as predicted by the four models of Table 5, and the difference between the actual rank and the predicted rank.

For 24 of the 30 universities all four models provide similar results. In particular, all four models would have predicted that the University of Technology, Sydney should have earned an ERA rank of 3, rather than 5. The data suggest that the University of Technology, Sydney is at 'the world standard' (however that is defined), and not 'well above the world standard'.

The Group of Eight universities are said to be research-intensive and generally hold the reputation of being Australia's best universities. All eight have an ERA rank of 4 - 'above world standard'. But only Monash has a fitted value of 4 (for three of the four models). Every other one of the other Group of Eight has fitted values of 3 - 'at world standard' - for all four models. In other words, there is evidence that the ERA process overestimated the ERA rank for, at least, seven of the eight Group of Eight universities. Random variation of the ERA process would suggest that only three or four of the Group of Eight ERA ranks would be overestimated, while three or four might be underestimated. It is extremely unlikely that seven would be overestimated if ranking errors were unbiased.

Griffith University has been the big loser from the ERA process. Three of the four models show a fitted value of 4 - 'above world standard' — while only one model (Model 4 - the least-preferred model) shows a fitted value of 3 - 'at world standard'. The ERA process actually allocated an ERA rank of 2 - below world average.

The evidence on Charles Darwin University is mixed. The two better models (Model 1 and Model 2) suggest that it should be ranked 'below world standard', while the less-preferred models (Model 3 and Model 4) suggest that its existing rank at the world standard is appropriate.

\section{Discussion}

The results shown in this paper are not mere quibbles. Given the time, effort and money invested in the ERA process, it is important to get the rankings and orderings correct (Trounson 2012a). It is not good enough to suggest that the difference between, say, an ERA rank of 2 and an ERA rank of 3 is a matter of subjective opinion. As the quotes from Matchett and Roberts in the introduction make clear, these numbers are important.

Furthermore, the Australian federal government has indicated that federal funding decisions will be decided on the basis of these rankings. To the extent that there is a deliberate and systematic upward bias for some universities, 
an attempt to bias federal funding has occurred. It is easy to imagine that misrepresentation for financial gain may be viewed by some as being unethical if not illegal.

At the same time, Trounson (2012b) reports that hiring decisions are being made on the basis of earned ERA ranks. ${ }^{16}$ Yet the analysis shown here indicates that some ERA ranks might be substantially overstated - on the objective evidence the University of Technology, Sydney is at world standard, not well above world standard. Similarly, some ERA ranks are substantially understated. Griffith University has an ERA rank of 2 - below world standard - while the objective evidence suggests that it should be ranked as being above the world standard. An uncritical application of the ERA data would see a world-standard research environment being funded and promoted while an above-worldstandard research environment being unfunded and not promoted. Given the stated aims of the ERA this would be a perverse result.

There may well be additional explanations for the ERA ranks that have been awarded. For example, the ERA included so-called esteem factors when forming their opinions as the world standing of research. The ERA Evaluation Handbook, however, states that esteem facts may be used to increase ERA ranks, but not reduce them. ${ }^{17}$ It could be that case that the seven of the eight Group of Eight universities that received higher ERA ranks than can otherwise be justified had very high esteem factors. The ERA Handbook provides examples of esteem as being editors of prestigious reference works, or various category 1 fellowships, or members of learned academies.

It might be possible that a small number of superstars are driving the results. University X may employ person $\mathrm{Y}$ and so generate a high ERA rank. This may happen, but would constitute a violation of the ERA rules. For example, under esteem measures, the ERA Evaluation Handbook states, 'Individual researchers cannot be identified through the esteem measures' ${ }^{18}$ Later we read, '[Research Evaluation Committee] members do not make comment about the contributions of individual researchers. ${ }^{19}$ Later again: 'Drill down menus are generally not available where information would allow the viewer to identify and track individual researchers. ${ }^{20}$

Ultimately, it is not at all clear why there is such a large discrepancy between the actual ERA ranks and objective information that can be derived from Scopus the ERA's chosen dataset. It is not surprising that most Australian universities should score at the world standard (however defined). What is surprising is that

16 http://www.theaustralian.com.au/higher-education/competition-hots-up-for-research-big-fish/storye6frgcjx-1226534758787.

17 Handbook: 22.

18 Ibid: 20 .

19 Ibid: 23.

20 Ibid. 
the Australian government and its research agency would claim that 14 out of 30 Australian universities were below the world standard without bothering to define what that standard might be. It is even more surprising that several universities could be ranked at above the world standard (or even well above the world standard) without any reliable objective evidence to support that ranking except for the 'expert and informed view' of the individuals making the ranking.

Until such time as the government or the ARC is capable of producing transparent and objective rankings, these rankings and this whole exercise should be viewed with some caution, if not scepticism and contempt.

\section{References}

Australian Research Council 2012, 'ERA 2012 Evaluation Handbook', Commonwealth of Australia; http://www.arc.gov.au/pdf/era12/ERA\%20 $2012 \%$ 20Evaluation \%20Handbook_final \%20for\%20web_protected.pdf

Matchett, S. 2012a, 'Big ERA is watching you', The AustralianHigher Education, 7 December 2012; http://blogs.theaustralian.news.com.au/thecommonroom/ index.php/theaustralian/comments/appalled_by_accountability/

2012b, 'Research race is on', The Australian Higher Education, 12 December 2012; http://blogs.theaustralian.news.com.au/thecommonroom/ index.php/theaustralian/comments/research_race_is_on/

Roberts, P. 2012, 'Dismal science's drive to mediocrity', The Australian Financial Review, 16 January 2012; http://www.afr.com/p/opinion/dismal_science_ drive_to_mediocrity_OU3Wv88THQHOclo3QeHKbN

Rodgers, J. and Valadkhanim, A. 2006, 'A Multi-Dimensional Ranking of Australian Economics Departments', Economic Record 82(256): 30-43.

Silva, P. 2012, 'More papers, better papers? The curious correlation of quality and quantity in academic publishing', The Australian Higher Education, 13 December 2012; http://www.theaustralian.com.au/higher-education/morepapers-better-papers-the-curious-correlation-of-quality-and-quantity-inacademic-publishing/story-e6frgcjx-1226535254934\#sthash.GvbqGhEJ.dpuf

Trounson, A. 2012a, 'ERA attacked for being too expensive, too detailed and too frequent', The Australian Higher Education, 8 December 2013; http://www. theaustralian.com.au/higher-education/era-attacked-for-being-too-expensivetoo-detailed-and-too-often/story-e6frgcjx-1226532299099\#sthash.Usgx3nR8. dpuf

2012b, 'Competition to hot up for research big fish in new ERA', The Australian Higher Education, 13 December 2012; http://www.theaustralian. com.au/higher-education/competition-hots-up-for-research-big-fish/storye6frgcjx-1226534758787\#sthash.lMy4opGt.dpuf 